\title{
PREDICTORS AND CORRELATES OF SELF-ESTEEM IN DEAF ATHLETES
}

\author{
Wakaki Uchida \\ Kyushu University \\ Herbert Marsh \\ Australian Catholic University \\ Kimio Hashimoto \\ Kumamoto Gakuen University
}

\begin{abstract}
*Corresponding author: Wakaki Uchida, Faculty of Human-Environment Studies, Kyushu University, 6-1 Kasuga-koen, Kasuga, Fukuoka 816-8580, Japan. Phone/Fax: +81-92-583-7852;

E-mail: uchida@ihs.kyushu-u.ac.jp
\end{abstract}

\begin{abstract}
The aims of this study were to examine the association between different aspects of self-esteem and level of sport competition and to assess the associations between self-esteem and age, length of participation in sport, and number of dramatic sport experiences in deaf athletes. One hundred and twelve congenitally deaf Japanese athletes completed the Self-Positiveness Scale (SPS) and the Inventory of Dramatic Experience for Sport (IDES). A correlational analysis demonstrated moderate to weak relationships between all of the SPS subscales except self-acceptance and public selfconsciousness. One-way ANOVAs revealed that international athletes had fewer negative relationships with others and more dramatic sport experiences. Multiple regression analysis indicated that dramatic sport experiences significantly predicted self-acceptance, self-achievement, life satisfaction, negative relationships with others, and self-disclosure. Thus, dramatic sport experiences can enhance some aspects of self-esteem.
\end{abstract}

Keywords: dramatic sport experiences, level of competition, duration of sport participation

\section{INTRODUCTION}

Interest in well-being has increased with the growth of positive psychology. This psychological approach focuses primarily on protecting the mental health of individuals (Sahin, 2013) by teaching people to cope with life's hardships and to create changes by developing positive qualities (Seligman \& Csikszentmihalyi, 2000). One focus of positive psychology is self-esteem, which is an important aspect of psychological well-being (Sahin, 2013; Shek \& McEwen, 2012).

Self-esteem is considered integral to the self-concept, and can be defined in terms of positive feelings about the self. It is integral to an individual's sense of their own value (Fox \& Corbin, 1989; Sonstroem, 1997), a principal component of mental health (Jambor $\&$ Elliott, 2005), a strong indicator of a healthy lifestyle (Hintermair, 2007), and an important indicator of well-being (Shek \& McEwen,
2012). Studies of self-esteem in deaf people suggest that the dominant hearing culture has relegated them to less valued social categories such as "handicapped" and "outsider" (Munoz-Baell \& Ruiz, 2000). Such prejudice, discrimination, and stigmatization are likely to be psychologically harmful (Crocker \& Major, 1989; Schick et al., 2013), a view echoed by Bat-Chava (2000), who found that deaf individuals have reduced self-esteem because of stigmatization of the Deaf community.

Although minority groups (e.g., racial/ethnic minorities, sexual-orientation minorities, and people with disabilities) often suffer stigmatization (Jambor \& Elliott, 2005; Johnson \& Yarhouse, 2013) and poor selfesteem, it is widely believed that membership of such a group has a protective effect on selfesteem because of the tendency to identify with the minority group (Crocker \& Major, 1989; Jambor \& Elliott, 2005). One way of boosting self-esteem is participation in sport. 
For deaf people, sport participation can establish a sense of belonging to the Deaf community because many deaf athletes do not use hearing aids or cochlear implants to communicate with hearing people, preferring to use sign language with other deaf athletes. There are numerous benefits of sport participation in terms of both physical and psychological well-being (e.g., self-esteem).

Self-esteem is an important psychological variable (Bardel, Fontayne, Colombel, \& Schiphof, 2010) and facet of personality (Adie, Duda, \& Ntoumanis, 2008) in competitive sport. Adie et al. (2008) demonstrated that individuals with higher selfesteem tend to perceive competitive sport as challenging, whereas individuals with lower self-esteem regard it as threatening. Although it is well known that participation in sport and physical activity can promote well-being, high-level competitive athletes participate in sport under conditions that present considerable physical and psychosocial stressors (Lundqvist, 2011). Elite athletes must continually strive for success in a highly competitive and stressful environment; thus, high-level competitive sport can have either a detrimental or beneficial influence on the wellbeing and health of athletes (Bartholomew, Ntoumanis, Ryan, \& Thogersen-Ntoumani, 2011). However, there is no research on the effects of competition level on deaf athletes' self-esteem.

Bat-Chava (1993) found evidence that positive school experiences are linked to higher self-esteem for deaf children. Positive experiences in other areas of life might also contribute to increasing self-esteem. For example, there is evidence that satisfying experiences in sport positively affect psychological well-being (Lundqvist, 2011). Researchers in Japan have studied the effect of "dramatic experiences in sport"; these refer to episodes that provide athletes with positive psychological development (e.g., enhanced self-concept), such as a dramatic "come-frombehind" finish, overcoming injury or failures, or flow experiences (Hashimoto, 2005). Hashimoto (2012) has suggested that the number of dramatic experiences in sport is more important for enhancement of positive psychological aspects than the duration of sport participation. However, there is no research examining the effects of the duration of participation or the number of experiences in sport on deaf athletes' self-esteem. As individuals with disabilities tend to lack positive experiences in their lives (Tam, 1998), it is pertinent to examine whether length of sport participation or positive experiences in sport settings are associated with positive self-esteem in deaf athletes.

Orth, Robins, and Widaman (2012) have claimed that self-esteem increases from adolescence to middle adulthood, reaches a peak at approximately 50 years, and then decreases in old age. The age range of athletes with disabilities is broad because it includes individuals with both congenital and acquired disabilities. Research is required to identify the relationship between psychological aspects of deaf athletes and demographic factors such as age (Tasiemski, Kennedy, Gardner, \& Blaikley, 2004). However, few studies have investigated the broader psychosocial outcomes of sport for deaf people (Punch \& Hyde, 2011). Therefore, the purpose of this study was to examine the association between self-esteem and level of competition in deaf athletes. A second aim was to examine whether age, duration of involvement in sport, and the number of dramatic experiences in sport are important predictors of self-esteem in deaf athletes.

\section{METHOD}

We used a cross-sectional design to explore the intrapersonal and interpersonal domains of self-esteem and to test whether dramatic experiences in sport are important for enhancing self-esteem in deaf athletes.

\section{Participants}

Participants were 66 male and 46 female congenitally deaf Japanese athletes. The mean age was 26.9 years $(S D=7.42)$. Among these athletes, 59 had participated in internationallevel competitions (e.g., the Deaflympics and the World Deaf Athletics Championships,) and 53 had participated in domestic-level competitions in Japan. The length of 
involvement in sport ranged from 1 to 31 years $(M=11.1, S D=5.98)$.

\section{Measures}

Participants completed two instruments assessing self-esteem and dramatic experiences in sport. These measures have been used in previous studies of athletes with disabilities (e.g. Uchida, 2013).

The Self-Positiveness Scale (SPS). The 41-item SPS was developed by Hiraishi (1993) to assess the components of selfesteem. This scale consists of a 19-item intrapersonal domain that measures selfacceptance (4 items), self-achievement (7 items), and life satisfaction (8 items), and a 22-item interpersonal domain that measures negative relationships with others ( 8 items), self-disclosure (7 items), and public selfconsciousness (7 items). The SPS has demonstrated moderate to high internal consistency; Cronbach's alpha was .69 for self-acceptance, .85 for self-achievement, .87 for life satisfaction, .86 for negative relationships with others, .80 for selfdisclosure, and .85 for public selfconsciousness (Hiraishi, 1993). Participants are asked to respond to a variety of statements about their self-esteem using 5-point Likert scales with anchors at 1 (strongly disagree) and 5 (strongly agree). Scale scores range from 4 to 20 for self-acceptance; from 7 to 35 for self-achievement, self-disclosure, and public self-consciousness; and from 8 to 40 for life satisfaction and negative relationships with others. Higher scores on self-acceptance, selfachievement, life satisfaction, and selfdisclosure, and lower scores on negative relationships with others and public selfconsciousness indicate positive self-esteem. Hiraishi (1993) did not specify the validity of the SPS; however, this scale has been used frequently in Japanese psychological research (e.g., Ishimoto, 2010; Sakai \& Watanabe, 2011; Shirakawa, Hamaguchi \& Okawa, 2012) and is listed in a prominent Japanese manual of psychological instruments (Hori \& Yamamoto, 2001).

The Inventory of Dramatic Experience for Sport (IDES). The IDES (Anan, 2012) is a Japanese scale used to assess dramatic experiences in a sport context. Anan (2012) developed the IDES using samples of high school and university student members of sports clubs. This scale consists of 26 items that require participants to rate their own experiences on a 5-point Likert scale ranging from 1 (strongly disagree) to 5 (strongly agree). The measure assesses experiences of overcoming injury, encouragement from significant others, self-contribution, overcoming failure, flow, finding solutions as a team, and achievement. Scale scores range from 26 to 130, with higher scores signifying more occurrences of dramatic experiences in sport. Internal consistency coefficients of the IDES range from .71 to .83 (Anan, 2012). A confirmatory factor analysis model was largely supported by the fit indices (GFI $=.92$, AGFI $=.90$, and RMSEA $=.05$ ) using samples of high school and university student members (Anan, 2012).

\section{Procedure}

Prior to participant recruitment, we obtained approval from the research ethics committee of the first author's university. Members of the Japanese Paralympic Committee approached coaches to help recruit participants. Coaches were provided with written information about the research and instructions on how to administer the questionnaires to their athletes.

Questionnaires were completed at a time convenient for the coaching staff, usually during the national training camp. Coaches gave participating athletes the questionnaire and a cover letter that explained the purpose of the study and indicated that data would remain confidential. We obtained informed consent for participation from each athlete. Questionnaires took approximately $15 \mathrm{~min}$ to complete. Participating athletes returned their questionnaires to the coaching staff during the national training camp and coaches mailed the questionnaires to the researcher. If athletes preferred, they could mail the questionnaire to the researcher directly. All data were collected over 8 weeks in November 2013. The data were screened, and there were no missing data.

\section{Data Analyses}


We first calculated descriptive statistics, coefficient alphas, and correlations for each of the six SPS subscales and for total IDES scores. We then used one-way analysis of variance (ANOVA) to examine differences in SPS and IDES scores by level of sport participation. A multiple regression analysis was used to examine whether self-esteem was predicted by age, the length of involvement in sport, and the number of dramatic sport experiences. Six separate multiple regression analyses were performed using the six SPS factors as dependent variables. All analyses used age, the length of involvement in sport, and the number of dramatic experiences in sport as independent variables. The forced entry method was used for all variables. We examined coefficients to assess the relationship between each dependent variable and the independent variables. Multicollinearity was examined prior to each of the six separate multiple regression analyses.

All data analyses were conducted using SPSS Statistics, Version 21 (IBM Corp., Armonk, NY).

\section{RESULTS}

Internal Consistency
Cronbach's alphas for the six SPS subscales and the total IDES scores were adequate: .85 for self-acceptance, .89 for selfachievement, .88 for life satisfaction, .89 for negative relationships with others, .82 for selfdisclosure, .88 for public self-consciousness, and .92 for dramatic experiences in sport scores.

\section{Descriptive Statistics and Correlations}

Means and standard deviations for the SPS and total IDES scores are shown in Table 1. Correlations among the SPS subscales are shown in Table 2. Of the 15 potential correlations, 14 were significant, but there was no significant relationship between selfacceptance and public self-consciousness. There were positive correlations among selfacceptance, self-achievement, life satisfaction, and self-disclosure, and between negative relationships with others and public selfconsciousness. Negative relationships with others correlated negatively with selfacceptance, self-achievement, life satisfaction, and self-disclosure. Public self-consciousness correlated negatively with self-acceptance, self-achievement, life satisfaction, and selfdisclosure. All correlations were moderate to weak.

Table 1. Descriptive Statistics and ANOVA Results for Scores on the Intrapersonal and Interpersonal Self-Esteem Subscales and the IDES

\begin{tabular}{|c|c|c|c|c|c|c|c|c|}
\hline \multirow[t]{2}{*}{ Participation } & \multicolumn{2}{|c|}{$\begin{array}{c}\text { Total } \\
(N=112)\end{array}$} & \multicolumn{2}{|c|}{$\begin{array}{l}\text { International } \\
\qquad(n=59)\end{array}$} & \multicolumn{2}{|c|}{$\begin{array}{c}\text { Non } \\
\text { international } \\
(n=53)\end{array}$} & \multirow[t]{2}{*}{$F$} & \multirow[t]{2}{*}{$\eta^{2}$} \\
\hline & $M$ & $S D$ & $M$ & $S D$ & $M$ & $S D$ & & \\
\hline \multicolumn{9}{|l|}{ Intrapersonal } \\
\hline Self-Acceptance $(\alpha=.85)$ & 17.2 & 2.72 & 17.5 & 2.35 & 16.9 & 3.08 & 1.30 & .01 \\
\hline Self-Achievement $(\alpha=.89)$ & 29.2 & 5.05 & 29.5 & 4.99 & 28.8 & 5.14 & .59 & .01 \\
\hline Life Satisfaction $(\alpha=.88)$ & 29.0 & 5.81 & 29.0 & 4.97 & 28.7 & 6.67 & .08 & .00 \\
\hline \multicolumn{9}{|l|}{ Interpersonal } \\
\hline $\begin{array}{l}\text { Negative Relationships with } \\
\text { Others }(\alpha=.89)\end{array}$ & 17.4 & 6.65 & 16.1 & 6.75 & 18.9 & 6.27 & $5.15^{*}$ & .10 \\
\hline Self-Disclosure $(\alpha=.82)$ & 25.5 & 4.47 & 25.9 & 4.77 & 25.0 & 4.10 & 1.18 & .01 \\
\hline $\begin{array}{l}\text { Public Self-Consciousness }(\alpha= \\
.88)\end{array}$ & 18.9 & 6.02 & 18.1 & 5.30 & 19.8 & 6.67 & 2.28 & .02 \\
\hline $\begin{array}{l}\text { Quantity of Dramatic } \\
\text { Experiences in Sport }(\alpha=.92)\end{array}$ & 97.7 & 16.62 & 100.6 & 14.02 & 94.3 & 18.69 & $4.16^{*}$ & .04 \\
\hline
\end{tabular}


Table 2. Correlations Between the Self-Esteem Subscales

\begin{tabular}{|c|c|c|c|c|c|c|}
\hline & Variables & 2 & 3 & 4 & 5 & 6 \\
\hline 1 & Self-Acceptance & $.62^{*}$ & $.33^{* *}$ & $-.37^{* *}$ & $.46^{* * 3}$ & -.09 \\
\hline 2 & Self-Achievement & & $.49^{* *}$ & $-.44^{* *}$ & $.53^{* *}$ & $-.24^{*}$ \\
\hline 3 & Life Satisfaction & & & $-.46^{* *}$ & $.52^{* *}$ & $-.34^{* *}$ \\
\hline 4 & Negative Relationships with Others & & & & $-.47^{* *}$ & $.49^{* *}$ \\
\hline 5 & Self-Disclosure & & & & & $-.36^{* *}$ \\
\hline 6 & Public Self-Consciousness & & & & & \\
\hline
\end{tabular}

\section{ANOVA}

The one-way ANOVAs indicated no differences between international and noninternational athletes on most of the selfesteem factors, $F(1,110)=.08-2.28, p>.05$. However, there was a significant effect of level of competition on negative relationships with others, $F(1,110)=5.15$, p < .05, with a moderately large effect size $\left(\eta^{2}=.10\right)$. International athletes scored lower than noninternational athletes on this subscale, but scored significantly higher on the number of dramatic experiences in sport, $F(1,110)=$ $4.16, p<.05$. The effect size was moderate $\left(\eta^{2}\right.$ $=.04)$.

\section{Multiple Regression Analysis}

Age correlated positively with the length of involvement in sport $(r=.35, p<.01)$ and with IDES scores $(r=.20, p<.05)$. Furthermore, the length of involvement in sport and IDES scores were significantly correlated $(r=.28, p<.01)$. We found no multicollinearity using tests of tolerance (values $=.83-.91)$ and the variance inflation factor (values $=1.10-1.20) . \quad \mathrm{F}$ values demonstrated that the multiple regression model was valid for self-acceptance $(F=9.33$, $p<.01)$, self-achievement $(F=12.13, p<$ $.01)$, life satisfaction $(F=4.46, p<.01)$, negative relationships with others $(F=5.10, p$ $<.01)$, and self-disclosure $(F=3.54, p<.05)$, but not for public self-consciousness $(F=$ $1.26, p>.05$ ).

Multiple regression analysis (see Table 3) showed that the number of dramatic experiences in sport significantly predicted self-acceptance $(\beta=.45, p<.01)$, self- achievement $(\beta=.51, p<.01)$, life satisfaction $(\beta=.31, p<.01)$, negative relationships with others $(\beta=-.28, p<.01)$, and self-disclosure $(\beta=.31, p<.01)$, but not public selfconsciousness $(\beta=-.11, p>.05)$. The coefficient of determination showed significant values for self-acceptance $\left(R^{2}=\right.$ $.18, p<.01)$, self-achievement $\left(R^{2}=.23, p<\right.$ $.01)$, life satisfaction $\left(R^{2}=.09, p<.01\right)$, negative relationships with others $\left(R^{2}=.10, p\right.$ $<.01)$, and self-disclosure $\left(R^{2}=.06, p<.05\right)$, but not for public self-consciousness $\left(R^{2}=.01\right.$, $p>.05)$. 
Table 3. Predictors of the Components of Self-Esteem

\begin{tabular}{|c|c|c|c|c|c|c|c|c|}
\hline \multirow[b]{2}{*}{ Variables } & \multicolumn{6}{|c|}{ Beta Coefficients } & \multirow[b]{2}{*}{ MBT } & \multirow[b]{2}{*}{ VIF } \\
\hline & $\begin{array}{l}\text { Self-Acceptance } \\
\qquad \begin{array}{c}\left(F=9.33^{* *}\right) \\
\left(R^{2}=.18^{* *}\right)\end{array}\end{array}$ & $\begin{array}{l}\text { Self-Achievement } \\
\qquad \begin{array}{c}\left(F=12.13^{* *}\right) \\
\left(R^{2}=.23^{* *}\right)\end{array}\end{array}$ & $\begin{array}{c}\text { Life } \\
\text { Satisfaction } \\
\left(F=4.46^{* *}\right) \\
\left(R^{2}=.09^{* *}\right)\end{array}$ & $\begin{array}{c}\text { Negative } \\
\text { Relationships } \\
\text { with Others } \\
\left(F=5.10^{*}\right) \\
\left(R^{2}=.10^{* *}\right) \\
\end{array}$ & $\begin{array}{l}\text { Self-Disclosure } \\
\qquad \begin{array}{c}\left(F=3.54^{* *}\right) \\
\left(R^{2}=.06^{*}\right)\end{array}\end{array}$ & $\begin{array}{c}\text { Public Self- } \\
\text { Consciousness } \\
\begin{array}{c}(F=1.26) \\
\left(R^{2}=.01\right) \\
\end{array}\end{array}$ & & \\
\hline Age & -.15 & -.12 & .13 & -.17 & -.01 & -.10 & .87 & 1.15 \\
\hline $\begin{array}{l}\text { Length of Time } \\
\text { Participating in } \\
\text { Sport }\end{array}$ & .02 & .02 & -.11 & .01 & -.07 & .17 & .83 & 1.20 \\
\hline $\begin{array}{l}\text { Quantity of } \\
\text { Dramatic } \\
\text { Experiences in } \\
\text { Sport }\end{array}$ & $.45^{* *}$ & $.51^{* *}$ & $.31^{* *}$ & $-.28^{* *}$ & $.31^{* *}$ & -.11 & .91 & 1.10 \\
\hline
\end{tabular}

Note. $\mathrm{MBT}=$ Multicollinearity between tolerance, $\mathrm{VIF}=$ Variance inflation factor.

${ }^{*} p<.05, \stackrel{* *}{p}<.01$. 


\section{DISCUSSION}

The aims of this study were to examine the association between self-esteem and level of competition in deaf athletes and to determine whether self-esteem was related to age, length of involvement in sport, and dramatic sport experiences.

The correlational analysis revealed moderate to weak relationships among all SPS subscales except between self-acceptance and public self-consciousness. The higher scores of self-acceptance, self-achievement, life satisfaction, and self-disclosure, and lower scores of negative relationships with others and public self-consciousness indicate that the participants experienced positive self-esteem. However, self-acceptance and public selfconsciousness were not significantly correlated. Our results demonstrate that participants who experience high selfacceptance do not necessarily experience public self-consciousness as well, and vice versa. Public self-consciousness - one aspect of self-consciousness-refers to the self as a social object; that is, the self as seen by others (Feginstein, Scheier, \& Buss, 1975). In deaf individuals, public self-consciousness might be affected by relationships with hearing people. Deaf individuals might develop public self-consciousness because they rely on nonverbal communication and the reactions of their hearing peers to provide cues to compensate for hearing difficulties.

Bartholomew et al. (2011) have highlighted the need for research examining whether high-level competitive sport has a detrimental or beneficial influence on athletes' well-being and health. Our results showed no significant differences in intrapersonal selfesteem, self-disclosure, and public selfconsciousness according to level of competition in sport. However, international athletes had more positive relationships with others and a higher number of dramatic experiences in sport compared to noninternational athletes. Our findings show that high-level competitive sport can have a beneficial influence on elite athletes even though they perform in a highly competitive and stressful environment. Additionally, deaf people who associate more closely with other deaf people report greater self-esteem than those who do not (Bat-Chava, 1993). International athletes may have more opportunities to participate in competition in deaf sporting events, where they can build relationships with other deaf athletes, deaf coaches, and deaf audiences.

We also found that international athletes had experienced a large number of dramatic sport episodes. However, our results do not provide evidence of causality. It may be that the athletes experienced many dramatic episodes in international competitions, suggesting that this setting can provide deaf athletes with good experiences for enhancing their self-esteem. Alternatively, the athletes may have had many dramatic experiences prior to their participation in international games, indicating that coaches and researchers might need to establish occasions during which athletes can experience dramatic episodes and help them evaluate their good experiences in training settings.

It is important to examine how selfesteem can be enhanced, particularly in individuals who may be at risk for well-being problems. Dramatic experiences in sport predicted various components of self-esteem, such as self-acceptance, self-achievement, life satisfaction, negative relationships with others, and self-disclosure, but age and the duration of sport participation did not. Our findings indicate that positive experiences in sport are better predictors of self-esteem than age or the duration of sport participation.

Although individuals with disabilities often report an absence of positive life experiences because of their disadvantaged social position (Tam, 1998), our results support the findings of Hashimoto (2012) that the number of dramatic experiences in sport is more important than duration of sport participation for enhancing positive psychological aspects. Orth et al. (2012) have suggested that self-esteem is a developmental factor related to age; however, our results 
indicate that the accumulation of positive experiences is crucial for deaf athletes independent of developmental stage and the duration of sport participation. Thus, it is important to encourage deaf individuals to participate in sport and to increase the number of dramatic sport experiences, which can positively affect their sense of self. Our findings indicate that further research is needed to clarify how self-esteem in deaf athletes develops as a result of dramatic experiences in sport. A complementary qualitative study could be useful in corroborating the current quantitative findings and generating more detailed information about dramatic experiences and how they are related to self-esteem.

\section{PERSPECTIVE}

The present paper suggests that international deaf athletes experience a large number of dramatic experiences in sport. Our findings indicate that the number of dramatic sport experiences is more important for enhancement of positive psychological aspects than age or duration of sport participation. For coaches, researchers, and practitioners in the field of adapted physical activity, this finding indicates the value of dramatic sport experience as an influence on self-esteem. It would appear that providing good opportunities for athletes to experience dramatic sport episodes is psychologically beneficial.

Because this was a cross-sectional study, it is difficult to establish causality. Future research could address this limitation by using both longitudinal and experimental studies to provide a developmental perspective on these factors. Despite its limitations, the present study considerably extends our insight into the relationships between predictors and correlates of self-esteem, and the importance of positive experiences for high self-esteem in deaf athletes.

\section{ACKNOWLEDGMENT}

This work was supported by JSPS

Grant-in-Aid for Young Scientists (B), Grant Number 23700731.

\section{REFERENCES}

Adie, J. W., Duda, J. L., \& Ntoumanis, N. (2008). Achievement goals, competition appraisals, and the psychological and emotional welfare of sport participants. Journal of Sport and Exercise Psychology, 30, 302-322.

Anan, Y. (2012). The inventory of dramatic experience for sport. In K. Hahimoto, A. Iiboshi, \& M. Negami (Eds.), Physical education in university: The theory and strategy for physical education research (pp. 280-281). Tokyo: Fukumura Shuppan (in Japanese).

Bardel, M., Fontayne, P., Colombel, F., \& Schiphof, L. (2010). Effects of match result and social comparison on sport state self-esteem fluctuations. Psychology of Sport and Exercise, 11, 171-176. doi: 10.1016/j.psychsport.2010.01.005

Bartholomew, K. J., Ntoumanis, N., Ryan, R. M., \& Thogersen-Ntoumani, C. (2011). Psychological need thwarting in the sport context: Assessing the darker side of athletic experience. Journal of Sport and Exercise Psychology, 33, 75-102.

Bat-Chava, Y. (1993). Antecedents of selfesteem in deaf people: A meta-analytic review. Rehabilitation Psychology, 38, 221-234. doi: 10.1037/h0080303

Bat-Chava, Y. (2000). Diversity of deaf identities. American Annals of the Deaf, 145, 420-428.doi: 10.1353/aad.2012.0176

Crocker, J., \& Major, B. (1989). Social stigma and self-esteem: The self-protective properties of stigma. Psychological Review, 96, 608-630. doi: 10.1037/0033295x.96.4.608

Feginstein, A., Scheier, M. F., \& Buss, A. H. (1975). Public and private selfconsciousness: Assessment and theory. Journal of Consulting and Clinical Psychology, 43, 522-527. 
Fox, K. R., \& Corbin, C. B. (1989). The physical self-perception profile: Development and preliminary validation. Journal of Sport and Exercise Psychology, 11, 408-430.

Hashimoto, K. (2005). Dramatic experiences in sport and life skills. Journal of Health, Physical Education and Recreation, 55 (February), 106-110 (in Japanese).

Hashimoto, K. (2012). Dramatic experience about sport. Coaching Clinic, (December), 71-74 (in Japanese).

Hintermair, M. (2007). Self-esteem and satisfaction with life of deaf and hard-ofhearing people: A resource-oriented approach to identity work. Journal of Deaf Studies and Deaf Education, 13, 278-300.

Hiraishi, K. (1993). A study on the development of self-consciousness in adolescence: The relation between selfconsciousness and perceived self by significant others. Bulletin of the School of Education, Nagoya University, 40, 99-125 (in Japanese).

Hori, H., \& Yamamoto, M. (Eds.). (2001). Collection of the Psychological Instruments. Vol. 1. Tokyo: Saiensu Sha (in Japanese).

Ishimoto, Y. (2010). The influence of a sense of "Ibasyo" on psychological and school adjustment in adolescence and emerging adulthood. The Japanese Journal of Developmental Psychology, 21, 278-286 (in Japanese).

Jambor, E., \& Elliott, M. (2005). Self-esteem and coping strategies among deaf students. Journal of Deaf Studies and Deaf Education, 10, 63-81. doi: 10.1093/deafed/eni004

Johnson, V. R. F., \& Yarhouse, M. A. (2013). Shame in sexual minorities: Stigma, internal cognitions, and counseling considerations. Counseling and Values, 58, 85-103. doi: $\quad 10.1002 / \mathrm{j} .2162-$ 007X.2013.00027.x

Lundqvist, C. (2011). Well-being in competitive sport-The feel-good factor? A review of conceptual considerations of well-being. International Review of Sport and Exercise Psychology, 4, 109-127. doi: 10.1080/1750984X.2011.584067
Munoz-Baell, I. M., \& Ruiz, M. T. (2000). Empowering the deaf. Let the deaf be deaf. Journal of Epidemiology and Community Health, 54, 40-44. doi: 10.1136/jech.54.8.561

Orth, U., Robins, R. W., \& Widaman, K. (2012). Life-span development of selfesteem and its effects on important life outcomes. Journal of Personality and Social Psychology, 102, 1271-1288. doi: 10.1037/a0025558

Punch, R., \& Hyde, M. (2011). Social participation of children and adolescents with cochlear implants: A qualitative analysis of parent, teacher, and child interviews. Journal of Deaf Studies and Deaf Education, 16, 474-493. doi: 10.1093/deafed/enr001

Sahin, K. (2013). Loneliness and life satisfaction in Turkish early adolescents: The mediating role of self-esteem and social support. Social Indicators Research, 111, 617-632.

Sakai, Y., \& Watanabe, T. (2011). "Selfexpression group-counseling" positive changes in self-consciousness: From a content analysis of student nurses before and after intervention in interpersonal relationships-that are difficult to. Journal of Academy of Nursing Education Research, 3, 15-27 (in Japanese).

Schick, B., Skalicky, A., Edwards, T., Kushalnagar, P., Topolski, T., \& Patrick, D. (2013). School placement and perceived quality of life in youth who are deaf or hard of hearing. Journal of Deaf Studies and Deaf Education, 18, 47-61. doi: 10.1093/deafed/ens039

Seligman, M. E. P., \& Csikszentmihalyi, M. (2000). Positive psychology: An introduction. American Psychologist, 55, 5-14. doi: 10.1037/0003-066X.55.1.5

Shek, Y. L., \& McEwen, M. K. (2012). The relationships of racial identity and gender role conflict to self-esteem of Asian American undergraduate men. Journal of College Student Development, 53, 703718. doi: $10.1353 /$ csd.2012.0065

Shirakawa, Y., Hamaguchi, Y., \& Okawa, I. (2012). Investigation of differences in scores of a positive sense of self and 
feeling of depression among patients with removed or conserved larynxes. Tsukuba Psychological Research, 43, 43-48 (in Japanese).

Sonstroem, R. J. (1997). Exercise and selfesteem. In W. P. Morgan (Ed.), Exercise and mental health (pp. 128-143). Washington, DC: Taylor \& Francis.

Tam, S. (1998). Comparing the self-concepts of persons with and without physical disabilities. Journal of Psychology, 132, 78-86. doi: 10.1080/00223989809599266
Tasiemski, T., Kennedy, P., Gardner, B. P., \& Blaikley, R. A. (2004). Athletic identity and sport participation in people with spinal cord injury. Adapted Physical Activity Quarterly, 21, 364-378.

Uchida, W. (2013). Correlation factors of dramatic experience for sport in the athletes with acquired disabilities. Annual Report of Grant-in-Aid for Challenging Exploratory Research, 38-42 (in Japanese). 